\title{
Macromolecular crowded conditions strengthen contacts between mouse oocytes and companion granulosa cells during in vitro growth
}

\author{
Shizuka MIZUMACHI ${ }^{1)^{*}}$, Taiki ARITOMI ${ }^{2 *}$, Kuniaki SASAKI ${ }^{3)}$, Kazuei MATSUBARA ${ }^{1)}$ and \\ Yuji HIRAO4)
}

\author{
${ }^{1)}$ Graduate School of Agriculture, Iwate University, Iwate 020-8550, Japan \\ ${ }^{2)}$ Department of Bioscience, Tokyo University of Agriculture, Tokyo 156-8502, Japan \\ ${ }^{3)}$ Laboratory of Electron Microscope, Division of Technical Support, Iwate University, Iwate 020-8550, Japan \\ ${ }^{4)}$ Institute of Livestock and Grassland Science, NARO, Ibaraki 305-0901, Japan
}

\begin{abstract}
Macromolecular crowded culture medium formed by addition of polyvinylpyrrolidone (PVP; molecular weight $=360000$ ), positively influences the viability, growth, and development of bovine oocytes. Owing to its apparently various effects, uncovering the specific mechanisms of crowding responsible for these outcomes is important. The present study was conducted to determine the effects of crowding on oocytes with a particular focus on the intimacy of contacts between oocyte and cumulus/granulosa cells. Growing mouse oocyte-granulosa cell complexes were cultured for 10 days in a modified $\alpha$-minimum essential medium, supplemented with PVP at a concentration of $0 \%, 1 \%, 2 \%$, or $3 \%(\mathrm{w} / \mathrm{v})$. Although the complexes developed in all groups, $2 \%$ and 3\% PVP medium induced a substantial morphological modification, and a larger proportion of oocytes associated with cumulus cells survived in 3\% PVP medium than in the $0 \%$ or $1 \%$ PVP medium. No significant difference was found in the frequencies of polar body extrusion (78-88\%) and blastocyst formation (approximately 40\%) after in vitro fertilization among the experimental groups. Confocal laser scanning microscopy indicated a higher number of transzonal processes reaching the oocyte from cumulus cells in 2\% PVP medium than in 0\% PVP medium. Transmission electron microscopy depicted close adhesion of the oocyte with cumulus cells in 2\% PVP medium — bearing a resemblance to their in vivo counterparts - and loose adhesion in $0 \%$ PVP medium. In conclusion, we found that a mechanism for the action of crowded conditions involves the strengthening of contacts and communication between oocytes and companion cumulus/ granulosa cells.
\end{abstract}

Key words: Culture medium, Granulosa cell, Macromolecular crowding, Mouse, Oocyte growth

(J. Reprod. Dev. 64: 153-160, 2018)

M acromolecular crowding created in culture medium with the help of polyvinylpyrrolidone (PVP; average molecular weight $=360000$ ) was found to exert significant positive effects on viability, growth, and developmental competence of bovine oocytes during a 14-day culture period [1]. Morphology of oocyte-granulosa cell complexes was also affected by crowding [1]. These observations imply various effects of crowding on both oocytes and granulosa cells, and presumably on the interactions between these two cell-types, as there are bidirectional interactions between oocytes and granulosa cells that create a regulatory loop essential for oocytes to attain normal growth and development (reviewed in references [2-4]).

Macromolecular crowding refers to the effects attributed to volume exclusion by one soluble macromolecule for another [5]. The characterization of crowding-induced effects on macromolecules

Received: December 15, 2017

Accepted: January 9, 2018

Published online in J-STAGE: February 16, 2018

(C)2018 by the Society for Reproduction and Development

Correspondence: Y Hirao (e-mail: yujih@affrc.go.jp)

* S Mizumachi and T Aritomi contributed equally to this work.

This is an open-access article distributed under the terms of the Creative Commons Attribution Non-Commercial No Derivatives (by-nc-nd) License. (CC-BY-NC-ND 4.0: https://creativecommons.org/licenses/by-nc-nd/4.0/) in solutions have been extensively studied using theoretical and experimental approaches (reviewed in [5]). Recently, effects of extracellular crowding on cultured cells have been gathered increasing interest. Accumulating evidence has revealed that crowding enhances the deposition of extracellular matrix (ECM) proteins by human mesenchymal stem cells $[6,7]$ and fibroblasts $[8,9]$. Crowding also affects adhesion, proliferation, and migration behavior of mesenchymal stem cells [7] and adipogenic differentiation responses [6].

Of particular importance, crowded media accelerate a regulatory loop that is created by a series of cell-cell interactions [6]. Since the loop of bidirectional communication that develops between oocytes and granulosa cells is vital for oocytes [10], oocyte-granulosa cell complexes make an excellent model for investigating the effects of crowding. While granulosa cells are the nutrient supply lines for growing oocytes, oocyte-secreted factors promote granulosa cell proliferation [11] and establish the phenotypic heterogeneity seen in cumulus cells (near the oocyte) and mural granulosa cells [12]. Moreover, the maintenance of meiotic arrest of oocytes by granulosa cells also involves bidirectional interactions with cumulus and mural granulosa cells [13]. In this model, three types of cells are involvedthe oocyte, cumulus, and mural granulosa cells.

In our previous study on PVP supplementation [1], we initially speculated that culture medium crowded by macromolecules can affect 
the diffusion of paracrine or autocrine factors produced by oocytes and granulosa cells, since the movement of these factors in vivo is supposedly affected by other macromolecules (such as proteoglycans) in the extracellular matrix. Indeed, a significant promotion in oocyte growth was observed in conditions crowded by 4\% PVP [1]. Among the changes induced by crowding, we found it interesting that oocytes and companion cumulus cells were firmly attached [1]; this modification appeared directly related to the enhanced recovery rate of viable oocytes associated with companion cumulus cells. Crowding can influence the status of cell-cell contacts within oocyte-granulosa cell complexes; therefore, to test this notion, we first examined the viability and growth of mouse oocytes in the presence or absence of macromolecular crowding. Oocyte competencies in undergoing meiotic maturation, fertilization, and embryonic development were also compared. Second, we examined the effects of crowding on the status of contacts made by oocytes with companion cumulus/ granulosa cells.

\section{Materials and Methods}

\section{Chemicals}

Unless otherwise specified, chemicals were purchased from Sigma-Aldrich (St. Louis, MO, USA).

\section{Preparation of oocyte-granulosa cell complexes}

All mice procedures and care protocols were in accordance with the guidelines of the Committee on Animal Experimentation of Iwate University and Institute of Livestock and Grassland Science, The National Agriculture and Food Research Organization (NARO). Female mice (ICR strain; 11-12-day-old) ovaries were obtained and then preantral follicles were dissected out with needles. The follicles were then treated with $1 \mathrm{mg} / \mathrm{ml}$ collagenase (Wako, Osaka, Japan) in modified Eagle's minimum essential medium (MEM; Nissui Pharmaceutical, Tokyo, Japan) supplemented with 30\% (v/v) fetal bovine serum (FBS; Thermo Fisher Scientific, Waltham, MA, USA) for $10 \mathrm{~min}$ at $37^{\circ} \mathrm{C}$. The follicles after collagenase treatment are hereafter referred to as oocyte-granulosa cell complexes or OGC. The complexes were divided into four groups of approximately 20 complexes each. The day of OGC collection was designated Day 0 . A series of preliminary experiments for determining optimal basal culture conditions are described in the Results (Fig. 1).

\section{In vitro growth}

The culture medium used for in vitro growth (IVG) was $\alpha$-MEM (11900-024; Thermo Fisher Scientific) supplemented with $1 \mathrm{ng} / \mathrm{ml}$ follicle stimulating hormone (FSH) (recombinant human; R\&D Systems, Inc., Minneapolis, MN, USA), $150 \mu \mathrm{M}$ ascorbic acid 2-glucoside (AA2G; Hayashibara, Okayama, Japan), 5\% FBS, and $0.08 \mathrm{mg} / \mathrm{ml}$ kanamycin sulfate. The culture substrates were membrane inserts (Corning ${ }^{\mathrm{TM}}$ 354444; Thermo Fisher Scientific) set in 24-well culture plates. To the membrane inserts and well, $0.5 \mathrm{ml}$ of culture medium was added. Culture medium with $0 \%$ PVP was used for the first 2 days in all groups to ensure the same conditions for cell attachment to the membrane. On Day 2, the concentration of PVP was modified to $1 \%, 2 \%$, or $3 \%(\mathrm{w} / \mathrm{v})$, or remained $0 \%$. The cultures were housed in an incubator maintained at $37^{\circ} \mathrm{C}$ under an atmosphere
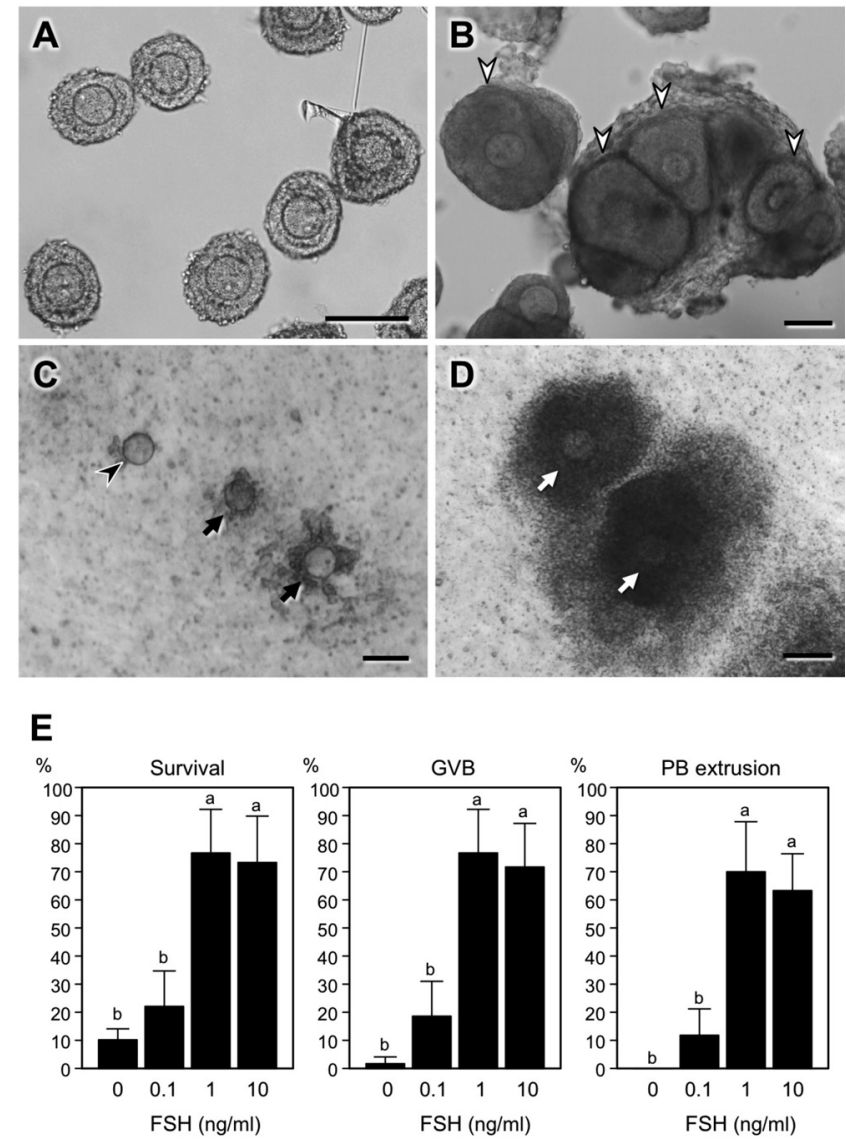

Fig. 1. Determination of basal culture conditions for oocyte growth. (A) Preantral follicles mechanically isolated from the ovary. (B) Follicles cultured without collagenase treatment and recovered after a 10-day culture period. Arrowheads indicate the basement membrane persistent throughout the culture period. (C) Oocytegranulosa cell complexes treated with collagenase and cultured for 10 days in medium without follicle stimulating hormone (FSH) supplementation. (D) Oocyte-granulosa cell complexes after a 10-day culture period in medium supplemented with 1 ng/ml FSH. (A-D) Scale bars $=100 \mu \mathrm{m}$. (E) Oocyte survival (Survival) and development (GVB, germinal vesicle breakdown; $\mathrm{PB}$ extrusion, first polar body extrusion) in culture medium with various concentrations of FSH. Data represents the mean \pm standard deviation of 3 replicates. Total numbers of oocytes used were 58, 59, 60, and 60 in culture medium supplemented with 0 , $0.1,1$, and $10 \mathrm{ng} / \mathrm{ml} \mathrm{FSH}$, respectively. ${ }^{\mathrm{a}, \mathrm{b}}$ Significant difference ( $\mathrm{P}<0.05$; Tukey's test $)$.

of $5 \% \mathrm{CO}_{2}$ in air, except during embryo culture as described below. Half of the medium was changed every other day. At the end of a 10-day culture period, oocytes and associated (cumulus) granulosa cells were removed from the membrane with a fine pipette. Oocytes firmly attached to cumulus cells (covering at least half of the oocyte surface) and those showing no signs of degeneration were considered surviving oocytes.

\section{In vitro maturation}

The modified $\alpha$-MEM used for IVG ( $0 \%$ PVP) was also used 
for maturation, except that $100 \mathrm{ng} / \mathrm{ml} \mathrm{FSH}$ and $10 \mathrm{ng} / \mathrm{ml}$ epidermal growth factor (EGF; Merck Millipore, Billerica, MA, USA) were further added to the medium. Oocyte-cumulus cell complexes were cultured in microdrops $(50 \mu \mathrm{l})$ of medium for $16 \mathrm{~h}$. As in a previous study [14], germinal vesicle breakdown and emission of the first polar body were used as indicators of meiotic resumption and progression to metaphase II, respectively. Images of the oocytes were taken (IMT-2; Optical, Tokyo, Japan) to measure the width of the zona pellucida.

\section{In vitro fertilization and embryo development}

Human tubal fluid (HTF) medium [15] supplemented with $3 \mathrm{mg} /$ $\mathrm{ml}$ bovine serum albumin (BSA) and $150 \mu \mathrm{M}$ AA2G was used for in vitro fertilization. Prior to insemination, epididymal spermatozoa obtained from the cauda epididymides were incubated at $37^{\circ} \mathrm{C}$ for $1 \mathrm{~h}$ in modified HTF medium, during which $0.4 \mathrm{mM}$ methyl- $\beta$ cyclodextrin was further added [16]. Oocytes were transferred to the sperm suspension $\left(4.0 \times 10^{5}\right.$ cells $\left./ \mathrm{ml}\right)$ and cultured for $6 \mathrm{~h}$. The oocytes were then completely denuded, examined for changes in morphology including the formation of pronuclei, and then cultured for $18 \mathrm{~h}$ in 50- $\mu 1$ microdrops of CZB medium [17] supplemented with $3 \mathrm{mg} / \mathrm{ml} \mathrm{BSA}, 150 \mu \mathrm{MAA} 2 \mathrm{G}$, and $50 \mu \mathrm{M}$ ethylenediaminetetraacetic acid (EDTA) in an atmosphere of $5 \% \mathrm{O}_{2}, 5 \% \mathrm{CO}_{2}$, and $90 \% \mathrm{~N}_{2}$. Embryos that had undergone first cleavage by $24 \mathrm{~h}$ after insemination were transferred to microdrops of KSOM supplemented with amino acids [18], $1 \mathrm{mg} / \mathrm{ml} \mathrm{BSA,} 150 \mu \mathrm{M} \mathrm{AA2G}$, and $50 \mu \mathrm{M}$ EDTA and incubated until $120 \mathrm{~h}$ after insemination.

\section{Confocal laser scanning microscopy}

For immunofluorescence microscopy, oocyte-cumulus cell complexes were denuded of cumulus cells by pipetting to expose the zona pellucida and then fixed with a $4 \%$ formaldehyde solution (Mildform; Wako, Osaka, Japan). Following a series of treatments with Triton $\mathrm{X}-100$ in phosphate buffered saline (PBS) and a blocking solution consisting of $20 \mathrm{mg} / \mathrm{ml} \mathrm{BSA}$ and $150 \mathrm{mM}$ glycine in PBS, oocytes were incubated for $30 \mathrm{~min}$ with $2 \mathrm{IU} / \mathrm{ml}$ phalloidin (Alexa Fluor 488; Thermo Fisher Scientific). Oocytes were then transferred into microdrops of a glycerol-based antifade solution (S2828; Thermo Fisher Scientific) supplemented with $10 \mu \mathrm{g} / \mathrm{ml}$ Hoechst 33342, which were prepared on glass bottom culture dishes (MatTek, Ashland, MA, USA), and then covered with oil. Microfilaments were visualized under a confocal laser scanning microscope (CLSM; Zeiss LSM 700; Carl Zeiss, Jena, Germany). Morphology of transzona processes (TZPs) traversing the zona pellucida was examined and the number of TZPs per $100 \mu \mathrm{m}$ along the perimeter of an oocyte was counted.

\section{Transmission electron microscopy}

To examine the status of contacts between the oocyte and cumulus cells, the complexes recovered on Day 10 were fixed with $2.5 \%$ glutaraldehyde in $0.1 \mathrm{M}$ phosphate buffer $(\mathrm{pH} 7.4)$ for $2 \mathrm{~h}$, followed by $1 \mathrm{~h}$ of post-fixation in $1 \%$ osmium tetroxide. Next, the samples were prepared for transmission electron microscopy by following the standard protocol. In brief, dehydrated complexes were embedded in araldite resin (a mixture of Poly/Bed 812 resin [Polysciences, Warrington, PA, USA], CY-212, DDSA [Nisshin EM, Tokyo, Japan], and DMP-30 [TAAB Laboratories, Berkshire, UK]) and serially sliced into ultrathin sections $(70-90 \mathrm{~nm})$ using a microtome (Ultracut;
Leica, Wetzlar, Germany). Sections were mounted on copper grids, stained with uranyl acetate and lead citrate, and then examined under a JEM-2100 microscope (JEOL, Tokyo, Japan) at $80 \mathrm{kV}$.

\section{Data presentation and statistical analyses}

Percentage data are represented by the means \pm standard deviation (SD). For statistical analyses of percentages obtained, the values were transformed by arcsine transformation. For simple and multiple comparisons, Student's $t$-test and Tukey's tests were used, respectively. For non-parametric multiple comparisons, Steel-Dwass tests were used. $\mathrm{P}$ values $<0.05$ were considered significant.

\section{Results}

\section{Morphology of oocyte-granulosa cell complexes}

Figure 1A shows preantral follicles after mechanical isolation; the follicles were treated with collagenase, otherwise the basement membrane persisted until the end of the culture period (Fig. 1B) resulting in growth impediment of the oocytes within intact follicles. Basement membranes may affect the movement of macromolecules and nanoparticles through the membrane [19] or physically hinder oocyte growth. In another preliminary series of experiments, the optimal dose of FSH was determined; without FSH supplementation, oocytes gradually became denuded (Fig. 1C), while $1 \mathrm{ng} / \mathrm{ml}$ of FSH promoted granulosa cell proliferation and maintained complex integrity (Fig. 1D). The addition of FSH also ensured acquisition of meiotic competence by IVG oocytes (Fig. 1E). Thus, culture medium supplemented with $1 \mathrm{ng} / \mathrm{ml} \mathrm{FSH}$ was used for subsequent experiments.

Within two days of culture onset, oocyte-granulosa cell complexes adhered to the substratum and grew outward. The complexes developed two prominent types of morphology, a dome-like structure that developed in $0 \%$ or $1 \%$ PVP medium (Fig. 2A, B) and a gentlysloping organization that developed in a rim pattern in $2 \%$ or $3 \% \mathrm{PVP}$ medium (Fig. 2C, D). In $0 \%$ or $1 \%$ PVP conditions, the complexes grew upwards in a round shape (Fig. $2 \mathrm{E}$ ), while in $2 \%$ or $3 \%$ PVP conditions, the complexes expanded more outwards than in the former conditions (Fig. 2F, G)

\section{In vitro oocyte growth and maturation}

The percentage of surviving IVG oocytes increased with respect to PVP concentration, exceeding $90 \%$ in medium supplemented with $2 \%$ or $3 \%$ PVP (Fig. 3A). Mean oocyte volume increased significantly by $80 \%, 68 \%, 77 \%$, and $81 \%$ from Day 0 to Day 10 in medium supplemented with $0 \%, 1 \%, 2 \%$, and $3 \%$ PVP, respectively (Fig. 3B). However, IVG oocytes remained smaller than those grown in vivo (Fig. 3B).

Cumulus cell mass grown in 2\% PVP medium was larger than those grown in $0 \%$ PVP medium (Fig. 4A, B) and complexes isolated after in vivo growth (Fig. 4C). Oocytes remained at the germinal vesicle stage in the tight cumulus cell mass by Day 10; only in response to hormonal stimulation did meiosis resume and cumulus cell mass expand (Fig. 4D-F). Production of the first polar body was observed in approximately $80 \%$ or more of oocytes grown in vitro. 

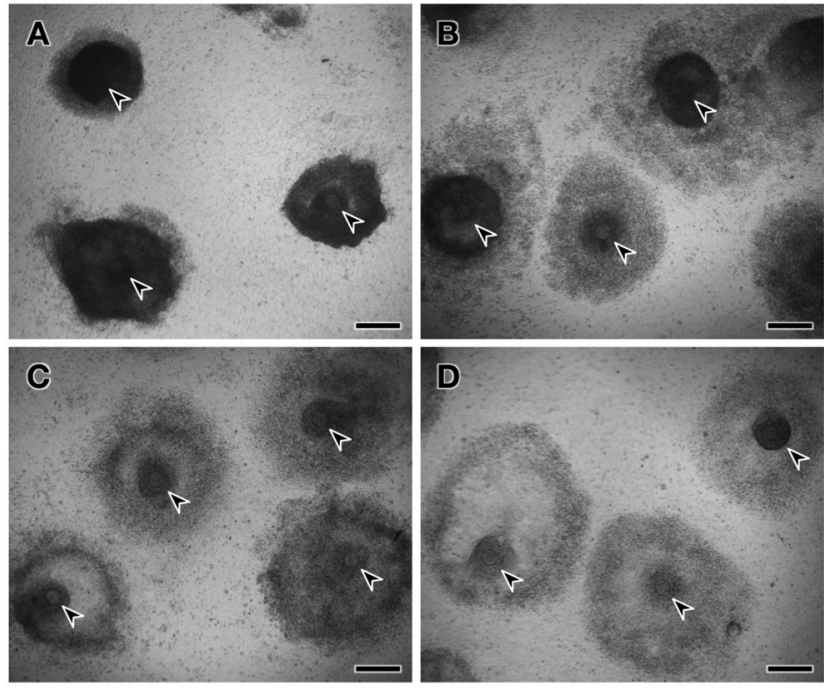

E
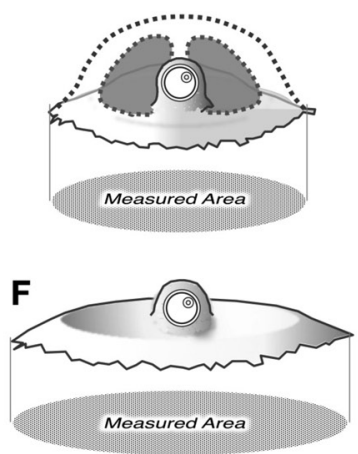

G $\mu \mathrm{m}^{2}$

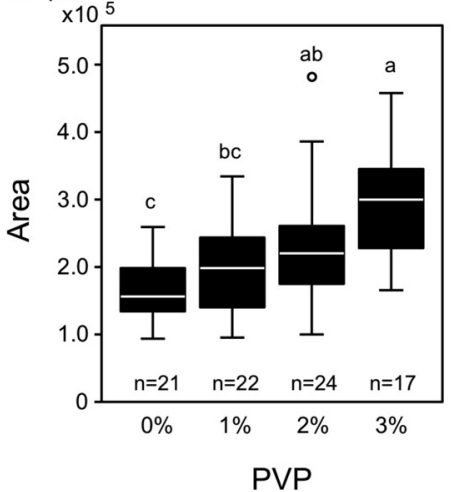

Fig. 2. Morphology of oocyte-granulosa cell complexes at the end of the 10-day culture period. (A-D) Complexes cultured in medium supplemented with $0 \%, 1 \%, 2 \%$, and $3 \%$ PVP. Arrowheads indicate oocytes. Scale bars $=200 \mu \mathrm{m}$. (E and F) Simplified illustration of oocyte-granulosa cell complex morphologies, with emphasis on the differences regarding form and "occupancy area". (G) Shaded areas in E and F (shown as measured area) were measured and compared. Images of oocyte-granulosa cell complexes and a stage micrometer were captured using a dissecting microscope (SZH; Olympus) and a digital camera (C3040Z; Olympus) at $64 \times$ magnification and viewed on a computer monitor at $120 \times$ total magnification. The areas covered by the complexes were measured using ImageJ.

\section{In vitro fertilization and embryonic development}

From the total number of oocytes initially used for culturing (Day 0), percentage of blastocyst formation was 28\%, 33\%, 40\%, and $30 \%$ in media supplemented with $0 \%, 1 \%, 2 \%$, and $3 \%$ PVP, respectively (Table 1). On the next day of in vitro fertilization, 70-77\% of in vitro-matured IVG oocytes underwent cleavage and 35-49\% developed to the blastocyst stage (Table 1). Crowded conditions during growth did not affect the number of cells that constituted the blastocysts (data not shown).
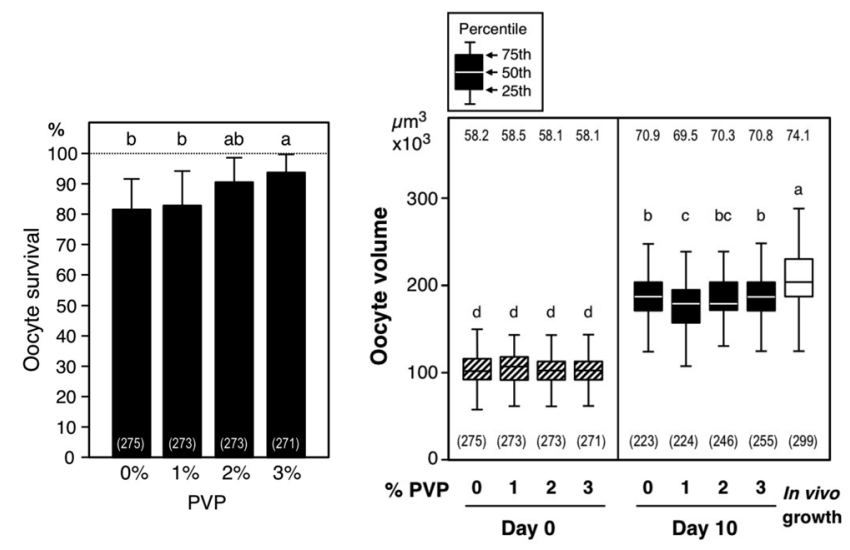

Fig. 3. Oocyte survival and growth in vitro. (A) Viability of oocytes cultured for 10 days in culture medium supplemented with various concentrations of PVP. Data represent the mean \pm standard deviation of 14 replicate experiments. ${ }^{\mathrm{a}, \mathrm{b}}$ Significant difference $(\mathrm{P}<0.05$; Tukey's test). (B) Oocyte volume on Day 0 and Day 10. Images of oocyte-cumulus/granulosa cell complexes and a stage micrometer were captured using an inverted microscope (IMT-2; Olympus) and a digital camera at $100 \times$ magnification and viewed on a computer monitor at a total magnification of 500 $x$ to measure oocyte diameter in $1 \mu \mathrm{m}$ increments. Oocyte volume was calculated using the diameter. Numbers above the box plots indicate the mean diameter $(\mu \mathrm{m})$ of oocytes. ${ }^{\mathrm{a}-\mathrm{d}}$ Significant difference $(\mathrm{P}<0.05$; Steel-Dwass tests). Total numbers of oocytes included are shown in parentheses.

\section{Zona pellucida, cumulus cells, and TZPS}

Thickness of the zona pellucida examined under light microscopy decreased with increasing PVP concentration (Fig. 5). On the other hand, observations using CLSM showed that there were more TZPs across the zona pellucida in 2\% PVP medium than in $0 \% \mathrm{PVP}$ medium (Fig. 6).

Finally, transmission electron microscopy of a cross-sectional profile of corona radiata and oolemma across the zona pellucida indicated the presence of submicron gaps between the zona pellucida and cumulus cells in $0 \%$ PVP medium (Fig. 7A-C), while cumulus cells in $2 \%$ PVP medium were tightly attached to the surface of the zona pellucida (Fig. 7D-F), revealing a morphology similar to that observed in vivo (Fig. 7G-H).

\section{Discussion}

In the present study, culture medium crowded by a high concentration of PVP sustained the integrity of oocyte-granulosa cell complexes for a longer period than conditions without PVP supplementation. Crowding also altered morphological organization of the complexes. These observations are in agreement with our previous findings for bovine oocytes and granulosa cell culturing [1]. In addition, more TZPs were found after growth in crowded conditions than in medium without PVP. Furthermore, oolemma, zona pellucida, and cumulus cells were found in closer contact in media crowded by PVP than in standard media, bearing a morphological resemblance to their in vivo counterparts. Thus, crowding affects a wide range of events, including oocyte viability, complex morphology, and intimate 

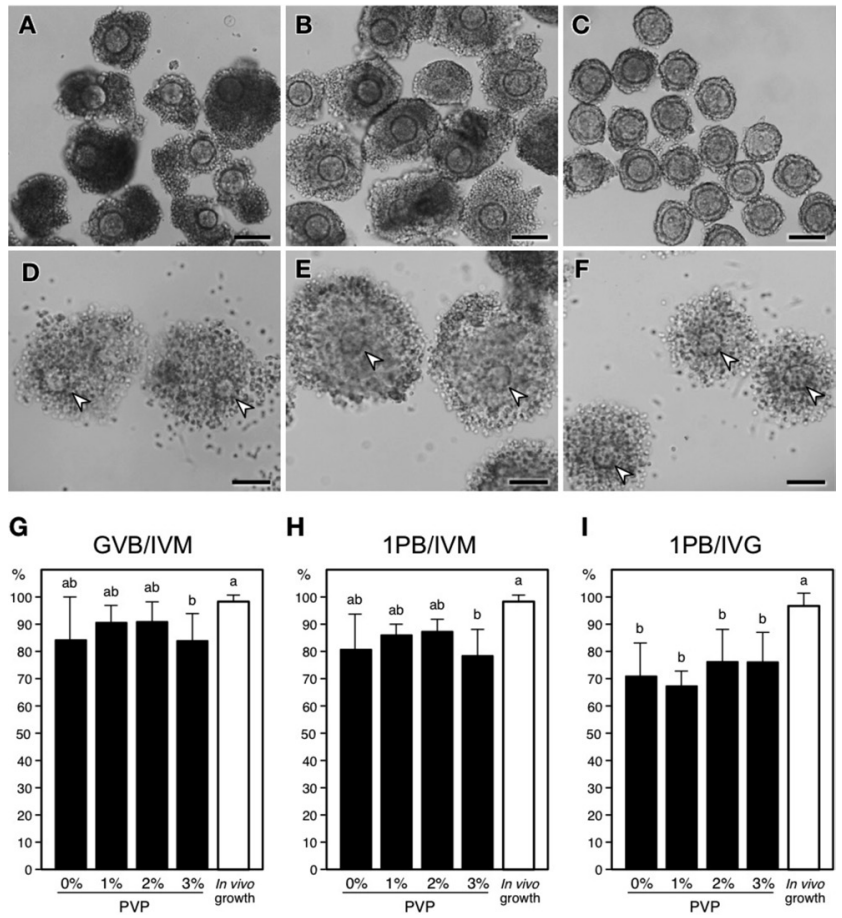

$\mathbf{H}$
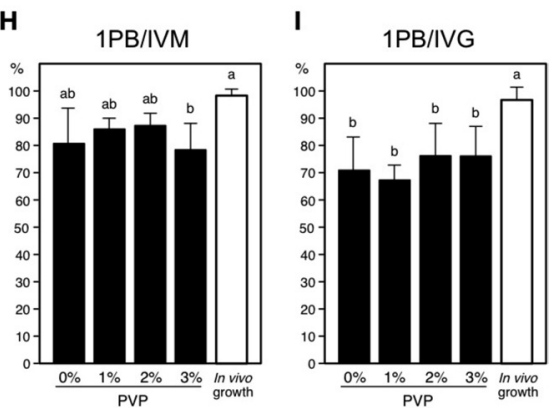

Fig. 4. Morphology of oocyte-cumulus cell complexes before and after in vitro maturation. Complexes recovered from (A) $0 \%$ PVP medium and (B) $2 \%$ PVP medium. Note the smaller size of complexes shown in (A) compared with (B). (C) Complexes collected from antral follicles of 24-day old mice. (D-F) Complexes with expanded cumulus cell mass derived from those shown in A-C. Arrowheads indicate oocytes. Scale bars $=100 \mu \mathrm{m}$. (G-I) Meiotic competence acquired during growth in vitro and in vivo. GVB, germinal vesicle breakdown; IVM, in vitro maturation; $1 \mathrm{~PB}$, first polar body extrusion; IVG, in vitro growth. $(\mathrm{G}$ and $\mathrm{H})$ Total numbers of oocytes used for IVM were $65,58,63$, and 71 from $0 \%, 1 \%, 2 \%$, and $3 \%$ PVP media, respectively. The number of in vivo grown oocytes used was 99 . (I) Total numbers of oocytes used for IVG were $74,73,73$, and 73 from $0 \%, 1 \%, 2 \%$, and $3 \%$ PVP media, respectively. ${ }^{\mathrm{a}, \mathrm{b}}$ Significant difference $(\mathrm{P}<0.05$; Tukey's test).

conjunction of oocytes with cumulus/granulosa cells across the zona pellucida. The crowding mechanisms of action responsible for these phenotypes may, at least in part, overlap.
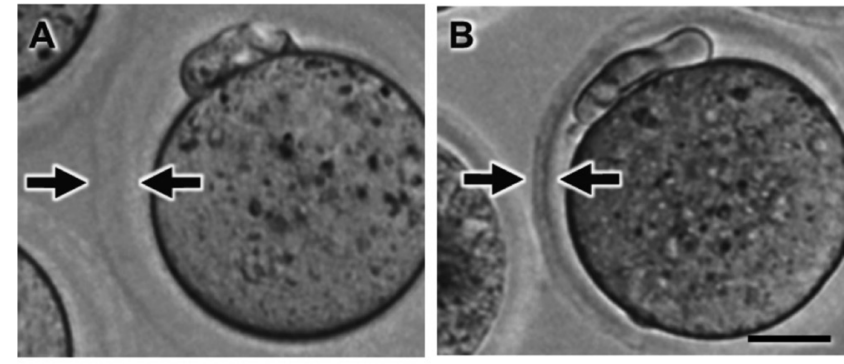

\section{C}

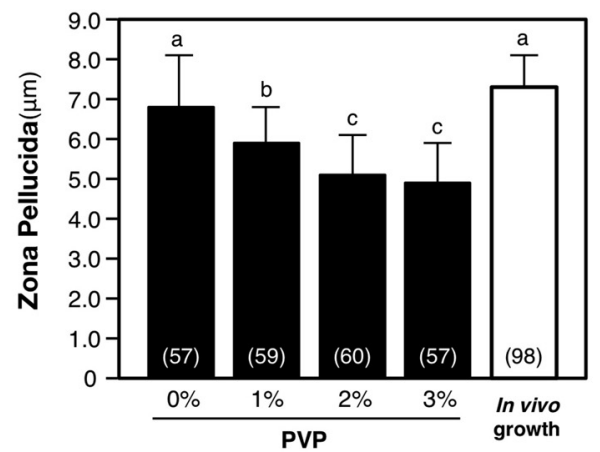

Fig. 5. Comparison of zona pellucida thickness after growth in culture medium supplemented with various concentrations of PVP. Typical appearance of zona pellucida of in vitro matured oocytes following growth in (A) $0 \%$ and (B) $2 \%$ PVP media. The distance between two arrows facing each other indicates width of zona pellucida. Images of denuded oocytes and a stage micrometer were captured using an inverted microscope and a digital camera at 200 $\times$ magnification and viewed on a computer monitor at $1000 \times$ total magnification. Width of zona pellucida was measured in $0.5 \mu \mathrm{m}$ increments. Scale bars $=20 \mu \mathrm{m}$. (C) Thickness of zona pellucida after growth in media with various PVP concentrations. Data are shown as the mean \pm standard deviation. Total numbers of oocytes used are shown in parentheses. ${ }^{\mathrm{a}-\mathrm{c}}$ Significant difference $(\mathrm{P}<0.05$; Tukey's test).

In the absence of crowded conditions, oocyte-cumulus cell complexes exhibited a reduced number of TZPs, fragility against mechanical stress induced by pipetting, and formation of submicron gaps between zona pellucida and cumulus cells. PVP supplementation mostly resolved or reduced these problems. An intense enlargement

Table 1. Developmental competence of mouse oocytes grown in culture medium supplemented with different concentrations of $\mathrm{PVP}^{\mathrm{a}}$

\begin{tabular}{lcccc}
\hline \multirow{2}{*}{ Growth } & \multirow{2}{*}{ PVP $(\mathrm{w} / \mathrm{v})$} & $\begin{array}{c}\text { No. of oocytes } \\
(\text { Day } 0)\end{array}$ & \multicolumn{2}{c}{ No. (mean $\% \pm \mathrm{SD}$ ) of } \\
\cline { 4 - 5 } & & 79 & $40(50.6 \pm 5.7)^{\mathrm{d}}$ & $22(28.0 \pm 10.7)$ \\
\hline In vitro & $0 \%$ & 80 & $46(57.5 \pm 12.5)^{\mathrm{d}}$ & $26(32.5 \pm 14.8)$ \\
& $1 \%$ & 80 & $50(62.5 \pm 5.6)^{\mathrm{d}}$ & $32(40.0 \pm 14.1)$ \\
& $2 \%$ & 80 & $50(62.5 \pm 15.2)^{\mathrm{d}}$ & $24(30.0 \pm 15.4)$ \\
In vivo $^{\mathrm{b}}$ & $3 \%$ & 141 & $123(87.8 \pm 8.9)^{\mathrm{c}}$ & $59(42.7 \pm 4.7)$ \\
\hline
\end{tabular}

${ }^{a}$ Data from 4 experiments. ${ }^{b}$ Fully grown oocytes were collected from 22 -day-old mice.

c, d Values with different superscripts are significantly different (Tukey's test, $\mathrm{P}<0.05$ ). 

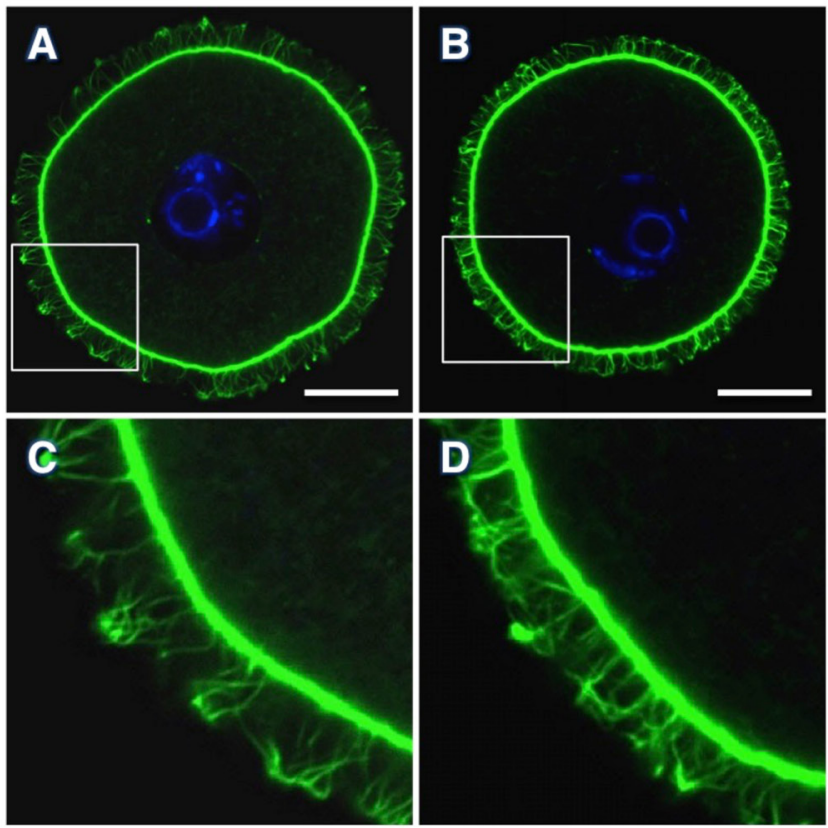

E

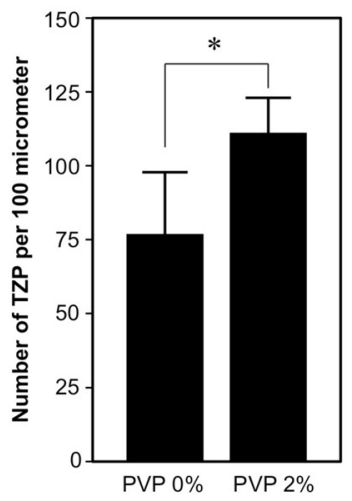

Fig. 6. Confocal images of actin (green) and chromosomes (blue) of oocytes grown in vitro. TZPs (green) remaining in the zona pellucida of oocytes grown in (A) $0 \%$ PVP and (B) $2 \%$ PVP media. Scale bars $=20 \mu \mathrm{m}$. (C and D) Enlarged image of TZPs shown in the insets of A and B. (E) Comparison of the number of TZPs per $100 \mu \mathrm{m}$ along the perimeter of the oocyte. Measurements were conducted on five oocytes for each group.

* Significant difference $(\mathrm{P}<0.05 ; t$-test $)$.
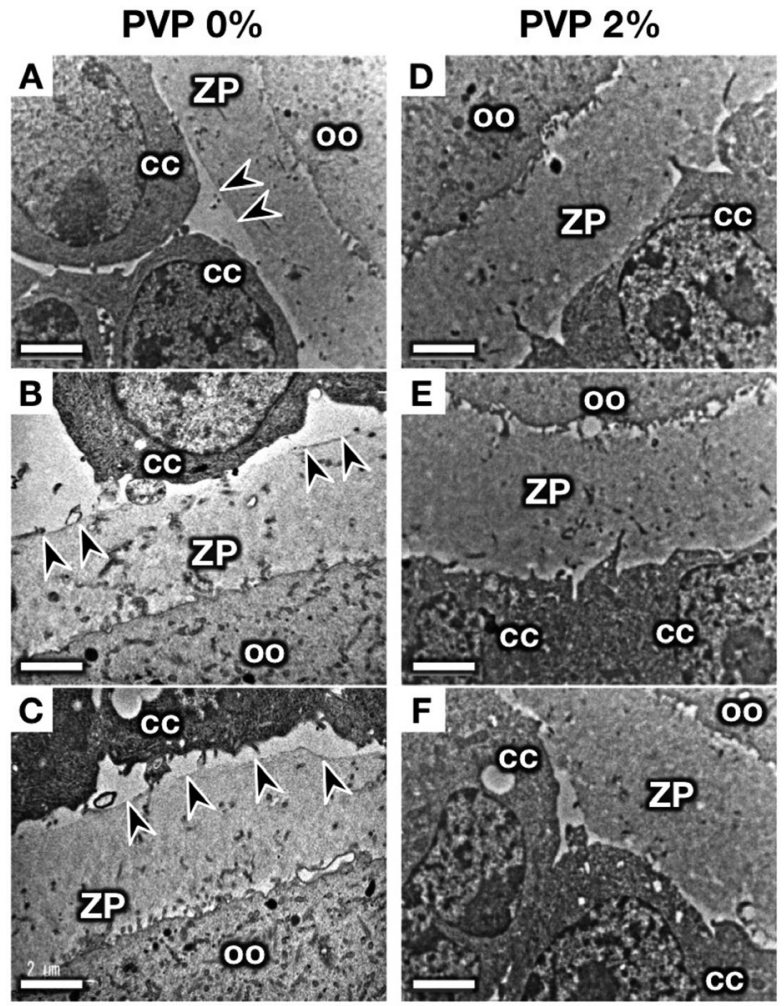

\section{In vivo growth}
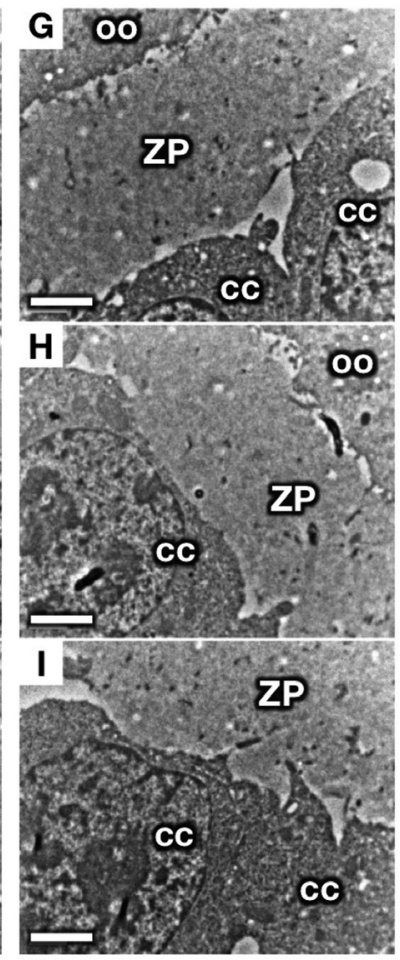

Fig. 7. Transmission electron microscopy of oocytes grown in vitro and in vivo. Each experimental group shows three different oocytes. (A-C) Oocytes grown in $0 \%$ PVP medium. Arrowheads indicate gaps observed between the zona pellucida and cumulus cells. (D-F) Oocytes grown in $2 \%$ PVP medium. (G-I) Oocytes grown in vivo. cc, cumulus cells; ZP, zona pellucida; oo, ooplasm. Scale bars $=2 \mu \mathrm{m}$. 
of the complexes around the oocyte in a rim pattern was observed in $2 \%$ and $3 \%$ PVP medium; this suggests that adhesion properties of granulosa cells to the substratum was altered, where crowdinginduced changes in the deposition of ECM proteins [6-9] may have been involved. Another novel observation was the enhanced growth of cumulus cell mass in crowded medium, suggesting the involvement of soluble mitogenic factor(s) produced by the oocyte [11]. It remains to be determined whether the tight packaging of oocyte-cumulus cell complexes was caused by behavioral changes of soluble factors, including ECM proteins, or by a more direct excluded volume effect in extracellular crowded medium. It seems plausible that crowding effects are manifested through a mixture of these mechanisms.

Oocyte growth may be disturbed when TZPs are insufficient in number; TZPs are the path connecting oocytes and granulosa cells [20], reaching the oolemma where gap junction communication is created, making TZPs indispensable for oocyte growth completion $[21,22]$. Considering that bidirectional communication creates a regulatory loop between the oocyte and granulosa cells [10], once communication becomes impaired, it may result in decreased formation of new TZPs.

Contrary to our expectations, however, no significant enhancement of oocyte growth was observed after the increase in TZPs by crowding. These observations are inconsistent with our previous findings on bovine oocytes - the growth of which was improved by crowded conditions [1]. This discrepancy may have occurred due to the larger size of bovine oocytes, as eventually, a bovine oocyte possesses 4-5 times the volume of a mouse oocyte. In retrospect, it was established that mouse oocytes at the mid-growth stage can attain full growth in vitro $[23,24]$ before we first used crowded medium for bovine oocytes [1]. In the present study, the mean oocyte diameter on Day 0 was $58.3 \mu \mathrm{m}$ and grew to $71.0 \mu \mathrm{m}$ by Day 10 in standard medium; this represents a $46 \%$ increase in oocyte surface area during growth in vitro. Perhaps substantial bidirectional communication was already established around the oocytes when they were isolated from the ovary. This point of view is supported by a recent study which documented a remarkable effect of $2 \%$ PVP on oocyte-granulosa cell complexes when oocytes had developed from the primordial germ cell stage in vitro [25].

Despite the increased number of TZPs traversing the zona pellucida, macromolecular crowding reduced the apparent thickness of the zona pellucida under light microscopy observations. On the other hand, transmission electron microscopy revealed submicron gaps between the zona pellucida and cumulus cells of complexes grown in standard medium. The presence of these gaps suggests that the cumulus cell layer facing the oocyte may not properly function as the mold for zona pellucida glycoproteins to fill. The resulting fluffy outer surface of the zona pellucida might make it look thicker than it actually is under a light microscope (Figs. 5 and 7). It also seems reasonable to assume that the gaps between the zona pellucida and cumulus cells may be responsible for the fragility of complexes grown in $0 \%$ PVP medium.

Viscosity was another property altered by the addition of PVP, as approximate viscosity was 1 and $6 \mathrm{mPa} \cdot \mathrm{s}$ at $25^{\circ} \mathrm{C}$ in medium supplemented with $0 \%$ and $2 \%$ PVP, respectively [1]. Although high viscosity may not be an essential requirement for creating effective macromolecular crowding conditions for mesenchymal stem cell cultures [26], it is important to resolve if culture medium viscosity was involved in the strengthening of contacts between oocytes and companion cumulus cells observed in the present study.

Finally, it should be noted that the optimal concentration of PVP varied depending on the primary interest of each examination. The addition of 3\% PVP was optimal in improving oocyte viability, although it appears to be less effective than 2\% PVP in terms of oocyte competencies of undergoing maturation and embryogenesis. The optimal concentration of PVP for oocyte growth also differed among different animal species [1,27]. Moreover, medium crowded by $4 \%$ PVP was suboptimal in supporting the maturation of bovine oocytes grown in vivo (Hirao et al., unpublished observations). Thus, deliberate application of crowded conditions may be a crucial strategy for achieving specific aims during cell culturing.

\section{Acknowledgments}

This work was supported in part by JSPS KAKENHI [grant number JP25114008 and JP22380151] and the National Agriculture and Food Research Organization (NARO), Japan.

\section{References}

1. Hirao Y, Itoh T, Shimizu M, Iga K, Aoyagi K, Kobayashi M, Kacchi M, Hoshi H, Takenouchi N. In vitro growth and development of bovine oocyte-granulosa cell complexes on the flat substratum: effects of high polyvinylpyrrolidone concentration in culture medium. Biol Reprod 2004; 70: 83-91. [Medline] [CrossRef]

2. Gilchrist RB, Lane M, Thompson JG. Oocyte-secreted factors: regulators of cumulus cell function and oocyte quality. Hum Reprod Update 2008; 14: 159-177. [Medline] [CrossRef]

3. Thomas FH, Vanderhyden BC. Oocyte-granulosa cell interactions during mouse follicular development: regulation of kit ligand expression and its role in oocyte growth. Reprod Biol Endocrinol 2006; 4: 19. [Medline] [CrossRef]

4. Russell DL, Gilchrist RB, Brown HM, Thompson JG. Bidirectional communication between cumulus cells and the oocyte: Old hands and new players? Theriogenology 2016; 86: 62-68. [Medline] [CrossRef]

5. Zhou HX, Rivas G, Minton AP. Macromolecular crowding and confinement: biochemical, biophysical, and potential physiological consequences. Annu Rev Biophys 2008; 37 375-397. [Medline] [CrossRef]

6. Ang XM, Lee MH, Blocki A, Chen C, Ong LL, Asada HH, Sheppard A, Raghunath M. Macromolecular crowding amplifies adipogenesis of human bone marrow-derived mesenchymal stem cells by enhancing the pro-adipogenic microenvironment. Tissue Eng Part A 2014; 20: 966-981. [Medline] [CrossRef]

7. Zeiger AS, Loe FC, Li R, Raghunath M, Van Vliet KJ. Macromolecular crowding directs extracellular matrix organization and mesenchymal stem cell behavior. PLOS ONE 2012; 7: e37904. [Medline] [CrossRef]

8. Lareu RR, Subramhanya KH, Peng Y, Benny P, Chen C, Wang Z, Rajagopalan $\mathbf{R}$, Raghunath M. Collagen matrix deposition is dramatically enhanced in vitro when crowded with charged macromolecules: the biological relevance of the excluded volume effect. FEBS Lett 2007; 581: 2709-2714. [Medline] [CrossRef]

9. Kumar P, Satyam A, Fan X, Collin E, Rochev Y, Rodriguez BJ, Gorelov A, Dillon S, Joshi L, Raghunath M, Pandit A, Zeugolis DI. Macromolecularly crowded in vitro microenvironments accelerate the production of extracellular matrix-rich supramolecular assemblies. Sci Rep 2015; 5: 8729. [Medline] [CrossRef]

10. Su Y-Q, Wu X, OBrien MJ, Pendola FL, Denegre JN, Matzuk MM, Eppig JJ. Synergistic roles of BMP15 and GDF9 in the development and function of the oocyte-cumulus cell complex in mice: genetic evidence for an oocyte-granulosa cell regulatory loop. Dev Biol 2004; 276: 64-73. [Medline] [CrossRef]

11. Gilchrist RB, Ritter LJ, Myllymaa S, Kaivo-Oja N, Dragovic RA, Hickey TE, Ritvos O, Mottershead DG. Molecular basis of oocyte-paracrine signalling that promotes granulosa cell proliferation. J Cell Sci 2006; 119: 3811-3821. [Medline] [CrossRef]

12. Diaz FJ, Wigglesworth K, Eppig JJ. Oocytes determine cumulus cell lineage in mouse ovarian follicles. J Cell Sci 2007; 120: 1330-1340. [Medline] [CrossRef]

13. Wigglesworth K, Lee K-B, OBrien MJ, Peng J, Matzuk MM, Eppig JJ. Bidirectional 
communication between oocytes and ovarian follicular somatic cells is required for meiotic arrest of mammalian oocytes. Proc Natl Acad Sci USA 2013; 110: E3723-E3729. [Medline] [CrossRef]

14. Eppig JJ, Schultz RM, OBrien M, Chesnel F. Relationship between the developmental programs controlling nuclear and cytoplasmic maturation of mouse oocytes. Dev Biol 1994; 164: 1-9. [Medline] [CrossRef]

15. Salahuddin S, Ookutsu S, Goto K, Nakanishi Y, Nagata Y. Effects of embryo density and co-culture of unfertilized oocytes on embryonic development of in-vitro fertilized mouse embryos. Hum Reprod 1995; 10: 2382-2385. [Medline] [CrossRef]

16. Takeo T, Hoshii T, Kondo Y, Toyodome H, Arima H, Yamamura K, Irie T, Nakagata N. Methyl-beta-cyclodextrin improves fertilizing ability of C57BL/6 mouse sperm after freezing and thawing by facilitating cholesterol efflux from the cells. Biol Reprod 2008; 78: 546-551. [Medline] [CrossRef]

17. Chatot CL, Ziomek CA, Bavister BD, Lewis JL, Torres I. An improved culture medium supports development of random-bred 1-cell mouse embryos in vitro. $J$ Reprod Fertil 1989; 86: 679-688. [Medline] [CrossRef]

18. Ho Y, Wigglesworth K, Eppig JJ, Schultz RM. Preimplantation development of mouse embryos in KSOM: augmentation by amino acids and analysis of gene expression. Mol Reprod Dev 1995; 41: 232-238. [Medline] [CrossRef]

19. Vllasaliu D, Falcone FH, Stolnik S, Garnett M. Basement membrane influences intestinal epithelial cell growth and presents a barrier to the movement of macromolecules. Exp Cell Res 2014; 323: 218-231. [Medline] [CrossRef]

20. Albertini DF, Combelles CM, Benecchi E, Carabatsos MJ. Cellular basis for paracrine regulation of ovarian follicle development. Reproduction 2001; 121: 647-653. [Medline] [CrossRef]

21. Ackert CL, Gittens JEI, OBrien MJ, Eppig JJ, Kidder GM. Intercellular communication via connexin43 gap junctions is required for ovarian folliculogenesis in the mouse Dev Biol 2001; 233: 258-270. [Medline] [CrossRef]

22. Simon AM, Goodenough DA, Li E, Paul DL. Female infertility in mice lacking connexin 37. Nature 1997; 385: 525-529. [Medline] [CrossRef]

23. Eppig JJ, Schroeder AC. Capacity of mouse oocytes from preantral follicles to undergo embryogenesis and development to live young after growth, maturation, and fertilization in vitro. Biol Reprod 1989; 41: 268-276. [Medline] [CrossRef]

24. Hirao Y, Miyano T, Kato S. Acquisition of maturational competence in in vitro grown mouse oocytes. J Exp Zool 1993; 267: 543-547. [Medline] [CrossRef]

25. Morohaku K, Tanimoto R, Sasaki K, Kawahara-Miki R, Kono T, Hayashi K, Hirao Y, Obata Y. Complete in vitro generation of fertile oocytes from mouse primordial germ cells. Proc Natl Acad Sci USA 2016; 113: 9021-9026. [Medline] [CrossRef]

26. Rashid R, Lim NS, Chee SM, Png SN, Wohland T, Raghunath M. Novel use fo polyvinylpyrrolidone as a macromolecular crowder for enhanced extracellular matrix deposition and cell proliferation. Tissue Eng Part C Methods 2014; 20: 994-1002. [Medline] [CrossRef]

27. Hashimoto S, Ohsumi K, Tsuji Y, Harauma N, Miyata Y, Fukuda A, Hosoi Y, Iritani A, Morimoto Y. Growing porcine oocyte-granulosa cell complexes acquired meiotic competence during in vitro culture. J Reprod Dev 2007; 53: 379-384. [Medline] [CrossRef] 